\title{
Super Antibiotics, Part IV. Hyperforin, Relative and Absolute Stereochemistry Elucidated by Gas-Chromatography Mass-Spectrometry with Supersonic Molecular Beams
}

\author{
Ilia Brondz \\ Norwegian Drug Control and Drug Discovery Institute (NDCDDI), Ski, Norway \\ Email: ilia.brondz@gmail.com
}

How to cite this paper: Brondz, I. (2017) Super Antibiotics, Part IV. Hyperforin, Relative and Absolute Stereochemistry Elucidated by Gas-Chromatography MassSpectrometry with Supersonic Molecular Beams. International Journal of Analytical Mass Spectrometry and Chromatography, 5, 70-85.

http://dx.doi.org/10.4236/ijamsc.2017.53005

Received: July 24, 2017

Accepted: September 22, 2017

Published: September 25, 2017

Copyright $\odot 2017$ by author and Scientific Research Publishing Inc. This work is licensed under the Creative Commons Attribution International License (CC BY 4.0).

http://creativecommons.org/licenses/by/4.0/

\begin{abstract}
Relative and absolute stereochemistry for hyperforin has been proposed by Brondz et al. was supported and new isomer of hyperforin-perforatrin has been discovered. Relative and absolute stereochemistry for perforatrin was proposed and elucidated by using gas-chromatography mass-spectrometry with supersonic molecular beams (SMB). The possibility of the existence of ambiguities in chirality as a hypothesis for the existence, and a new understanding, of chiral substances with shifting chirality is presented.
\end{abstract}

\section{Keywords}

Hyperforin, Perforatrin, Relative and Absolute Stereochemistry, Gas Chromatography-Mass Spectrometry, Chirality

\section{Introduction}

Hyperforin is one of the pharmaceutical active substances (PASs) in the plant Hypericum perforatum L., family Hypericaceae (Guttiferae). Hyperforin is a biologically active secondary metabolite in a class of prenylated phloroglucinol derivatives. Besides hyperforin, there are many other substances in genus Hypericum that are PASs which have the basic structure of hyperforin. The first use of hyperforin was as an antibacterial substance from extracts of $H$. perforatum $\mathrm{L}$. Hyperforin is now also medically accepted as an antidepressant. Hyperforin has multiple biological activities as medically useful PAS. Useful biological effects of hyperforin have been reported as being antibiotic, antifungal, antiviral, antiprotozoal, anticancer, immunomodulating, and others. Genera such as Garcinia, 
Clusia, Symphonia, Allanblackia, and Calophyllum also contain polyprenylated acylphloroglucinols, the main block of which contains hyperforin, as a structural basis. All these substances possess useful biological activities. Knowledge about the exact relative and absolute stereochemistry of hyperforin is important. Some confusion now exists regarding the relative and absolute structure of hyperforin introduced by Bystrov et al. Mistakes of Bystrov et al. are discussed in a paper "Super Antibiotics, Part III. Hyperforin, Revision of the Relative and Absolute Stereochemistry Presented by Bystrov et al.".

Further elaborations of the relative and absolute stereochemistry of hyperforin are necessary. The additional gas chromatography-mass spectrometry with supersonic molecular beams (GC-MS with SMB) evidence recorded by Brondz, and presented here, should clarify the subject. Possible reasons for the mistakes made by Bystrov et al. concerning the relative and absolute stereochemistry of hyperforin are discussed, and GC-MS with SMB evidence for the existence of isomer to hyperforin-perforatrin-is presented. Perforatrin is a new diastereomer (isomer) of hyperforin. The possibility of the existence of ambiguities in chirality as a hypothesis for the existence, and a new understanding, of chiral substances with shifting chirality is presented in the paper.

The necessity for tools in the struggle against infectious diseases became obvious at the beginning of the twentieth century. Massive epidemics that followed World War I heavily supported this idea. In the years 1920-1925, several publications describing observations in this field were presented [1] [2]. In 1928, the Scottish microbiologist Alexander Fleming observed antagonism of a mold toward Staphylococcus colonies in a petri dish [3]. In the former U.S.S.R., attention was directed towards antibacterial substances from plants [4]. Already during World War II, extracts from $H$. perforatum were used there. One of the antibacterial substances in the extract of $H$. perforatum was described as hyperforin [5].

Significant efforts were undertaken by the research team of Bystrov et al. (Academy of Sciences, U.S.S.R.) to determine the structure of hyperforin [6]-[11]. However, in successive publications [6] [10] [11], Bystrov et al. claimed different stereochemistry and chirality for hyperforin there were inconsistencies. In [6], they stated that hyperforin has a configuration of $6 S$ and $7 R$, but in [10] and [11], they stated that it has a configuration of $7 R$ and $8 S$-they changed their mind. The chiral centers $C 1$ and $C 5$ [6] were also relocated to $C 5$ and $C 1$, respectively, in [10] and [11]. In these three papers ([6] [10], and [11]), the chirality of $\mathrm{C} 1$ and $\mathrm{C} 5$ is confusing.

The chiralities of C 1 and C 5 are conflicting and can only be deduced from figures presented in these publications and for more information (see in a paper 'Super Antibiotics: Part III. Hyperforin, Revision of the Relative and Absolute Stereochemistry Presented by Bystrov et al.'). Figures of the hyperforin structure presented in [6] [10], and [11] are now shown here in Figure 1 (structures reproduced from the three references mentioned). The numbers in red have been 


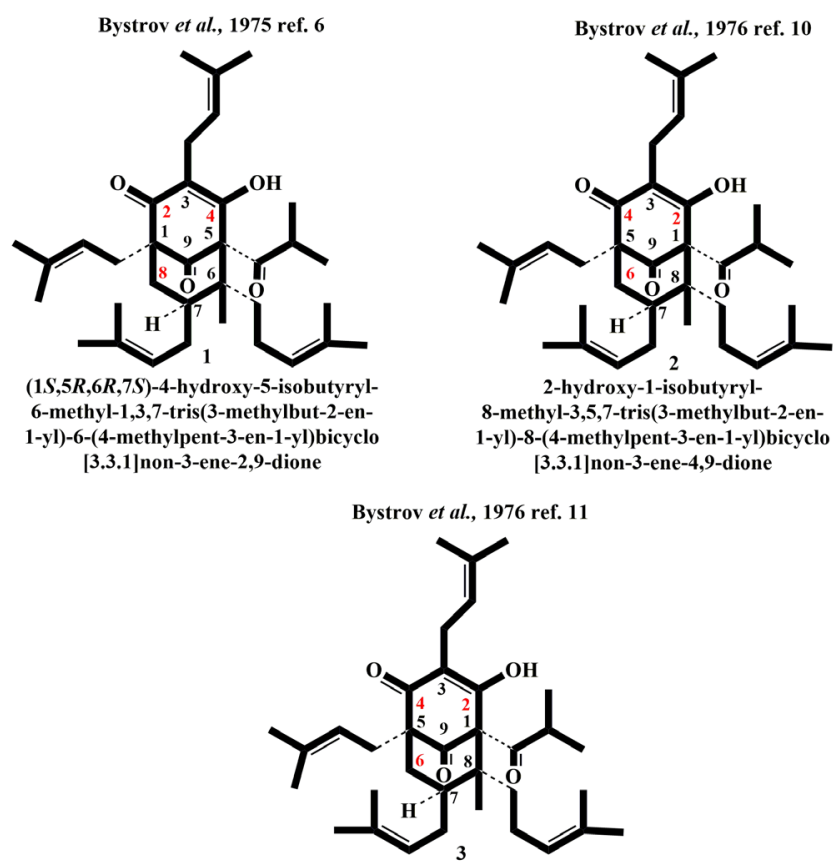

Figure 1. Structures of hyperforin published by Bystrov et al. in [6] [10], and [11]. (Numbering of carbon atoms in red and naming of structures following IUPAC rules were done by the author of this paper).

added by the author of this paper to simplify understanding. The numbering of the $\mathrm{C}$ atoms as published in [11] contradicts the rules pertaining to the numbering of $\mathrm{C}$ atoms accepted by IUPAC. If the numbering of $\mathrm{C}$ atoms in the structure proposed by Bystrov et al. [10] and [11] is used, then the name of the substance should be 2-hydroxy-1-isobutyryl-8-methyl-3,5,7-tris(3-methylbut-2-en-1-yl)-8(4-methylpent-3-en-1-yl)bicyclo[3.3.1]non-3-ene-4,9-dione [10]. The configuration of new chirality at C 7 as $R$ and C 8 as $S$ is as stated [11].

Up until 1978, Bystrov et al. published structures of hyperforin. Brondz et al. then notified them about confusion in the structures. Because of the significant irregularities observed in the structures published by Bystrov et al. ([6] [10], and [11]), in 1978, Brondz (University of Oslo, Norway) initiated a project to clarify the content of $H$. perforatum $\mathrm{L}$. and reconsider the relative and absolute stereochemistry of hyperforin. In the same year (1978), Brondz et al. notified Bystrov et al. that our data suggested errors in their claim regarding the stereochemistry of hyperforin. Results of Brondz et al. first reinvestigation into $H$. perforatum and hyperforin were presented in 1979 [12]. The antibacterial spectrum and mass spectrum of hyperforin were also studied, and reported in [12]. The composition of $H$. perforatum was reviewed in [13] and [14]. The first mass spectrum of hyperforin, recorded using chemical ionization, was obtained in 1978 and published in 1979 [12] (see Figure 2). Using X-ray crystallography, the relative and absolute stereochemistry of hyperforin has been elucidated, as reported in [15] and [16], respectively. Figure 3 shows the structure of the $p$-bromobenzoate ester of hyperforin (1) and hyperforin (2). 


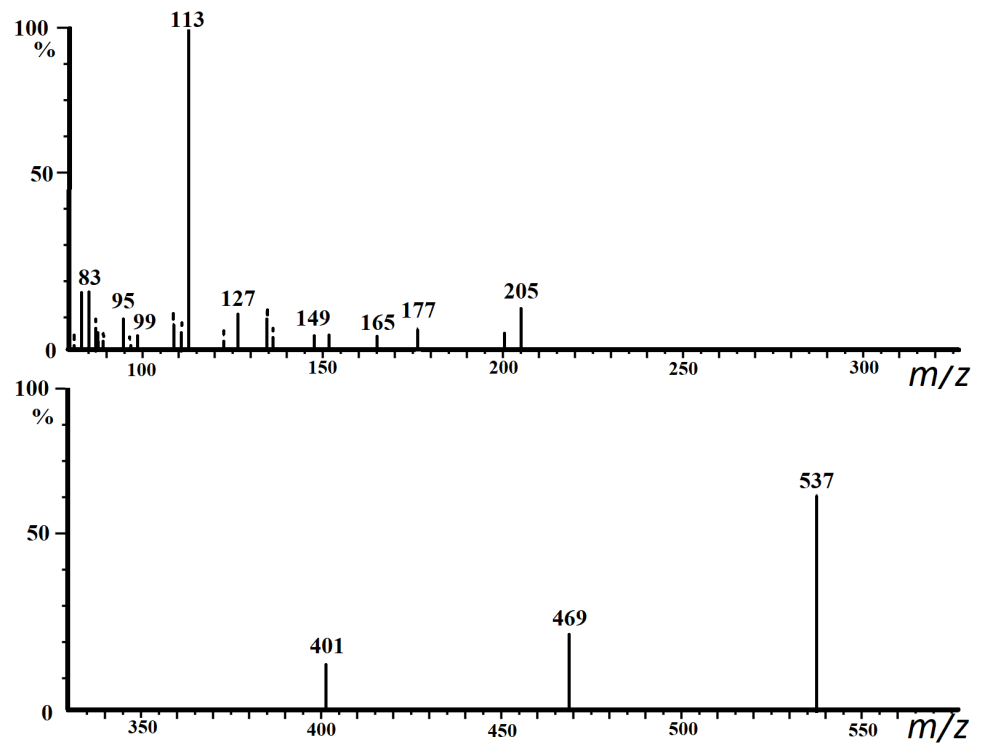

Figure 2. Mass spectrum of hyperforin (recorded using chemical ionization mass spectrometry), as presented in [12].

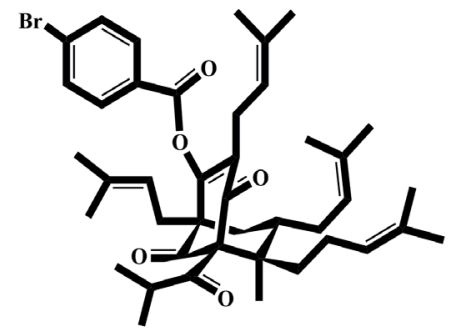

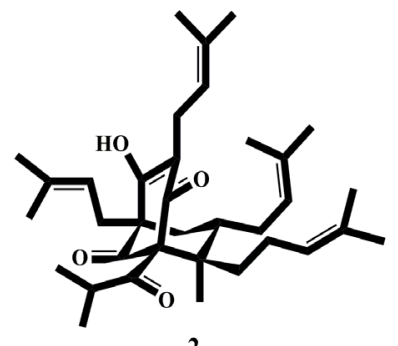

2

$(1 R, 5 R, 7 S, 8 R)-4$-hydroxy-1-isobutyryl-8methyl-3,5,7-tris(3-methylbut-2-en-1-yl)8-(4-methylpent-3-en-1yl)bicyclo[3.3.1] non-3-ene-2,9-dione tris(3-methylbut-2-en-1-yl)-6-(4-methylpent-3en-1-yl)-4,9-dioxobicyclo[3.3.1]non-2-en-2-yl 4-bromobenzoate

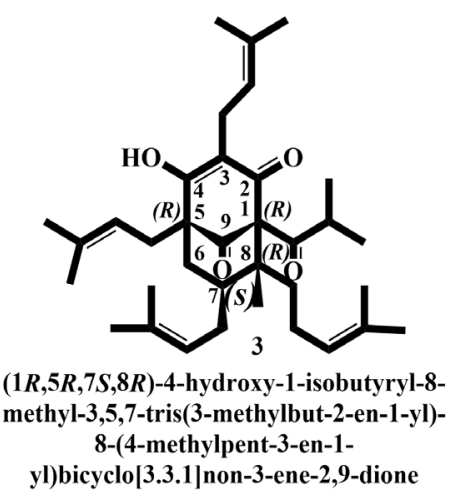

Figure 3. Structures of (1) p-bromobenzoate ester of hyperforin [16] and (2) hyperforin, and (3) two-dimensional perspective of hyperforin, with numbering of $\mathrm{C}$ atom numbers and chirality.

Hyperforin is a thermolabile substance that is easily oxidized by oxygen or air. At the time of X-ray analysis of the relative configuration [15] and absolute configuration [16], it was not yet being possible to undertake chromatography-mass 
spectrometry analysis to confirm the purity of crystals. The oxidative analysis of crystals gave $95 \%$ and $97 \%$ compliance with dinitro-benzoate of hyperforin [15] and $p$-bromobenzoate of hyperforin [16], respectively. Quantities of impurities present in crystals did not interfere with the results of X-ray analysis.

A sample of the $p$-bromobenzoate ester of hyperforin was placed in a glass ampule under Ar gas (high quality; Norsk Hydro AS, Norway), the ampule was soldered and then capped in liquid nitrogen until required for the gas-chromatography mass spectral analysis described in the present paper. Results of GCMS with SMB analyses are shown in figures presented in the next section (Materials and Methods).

\section{Materials and Methods}

The above sample of transparent white crystals of the $p$-bromobenzoate ester of hyperforin (described in [16]) $(1.0 \mathrm{mg})$ was dissolved in $n$-hexane ( $1 \mathrm{~mL}$; analytical grade reagent, Merck, Darmstadt, Germany). GC-MS analysis with supersonic molecular beams (SMB) instrumentation enabling the separation and analysis of thermolabile substances is described in detail in [17] and [18]. The actual instrumentation used here for GC-MS with SMB was based on a Varian 1200 GC-MS system (Varian, Middleburg, The Netherlands); details are described in [19]. Separation of substances and resolution of isomers was carried out on a VF-5HT column (Varian, Middleburg, The Netherlands): $4 \mathrm{~m}$ length, $0.25 \mathrm{~mm}$ i. d., $0.1 \mu \mathrm{m}$ film thickness. The reduction of column length was done in the laboratory. The flow rate of helium in the column was $8 \mathrm{~mL} / \mathrm{min}$. A sample extract in $n$-hexane $(1 \mu \mathrm{L}$; approximate concentration $100 \mathrm{ppm})$ was injected (split ratio of 10:1), using the Varian 1079 injector, at $230^{\circ} \mathrm{C}$. The $\mathrm{GC}$ oven was programmed from $120^{\circ} \mathrm{C}$ to $300^{\circ} \mathrm{C}$ at $20^{\circ} \mathrm{C} / \mathrm{min}$. Separation of substances, the resolution of isomers, and the detection of compounds in crystals of the p-bromobenzoate ester of hyperforin are shown as a TIC chromatogram in Figure 4. The MS fragmentation of substances of MS peaks is shown in Figure 5 and Figure 6.

\section{Results and Discussion}

Figure 7 shows the structure of the p-bromobenzoate ester of hyperforin [16], together with the percentage composition of elements in crystals analyzed by oxidative analysis and the theoretical calculated Molecular Weight (MW) (in Dalton) and mass $\mathrm{m} / \mathrm{z}$ of $\mathrm{M}^{+}$. Bromine ${ }_{35} \mathrm{Br}$ has 30 known radioisotopes, however, only two stable isotopes are known: ${ }^{79} \mathrm{Br}$ and ${ }^{81} \mathrm{Br}$. For this reason, the masses $m / z 719,720$, and 721 are present in the mass spectrum of the $p$-bromobenzoate ester of hyperforin. The appearance of two isomers, A and B, of hyperforin supports the correctness of the relative and absolute stereochemistry of the molecule [15] [16], and can partially explain the mistakes in the publications of Bystrov et al.; in reports [6] [10], and [11].

Hyperforin in free form is a keto-enol molecule, which is subjected to keto- 


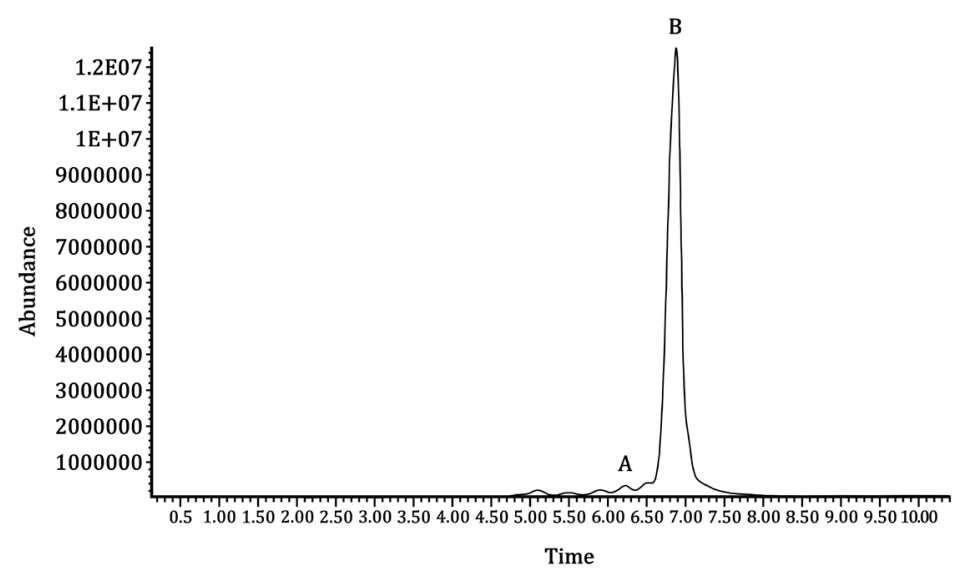

Figure 4. Composition of $p$-bromobenzoate ester of hyperforin crystals [16] shown as a TIC chromatogram. Peak $\mathrm{A}$ is the minor isomer of $p$-bromobenzoate ester of hyperforin, and peak $\mathrm{B}$ is the major isomer of $p$-bromobenzoate ester of hyperforin.

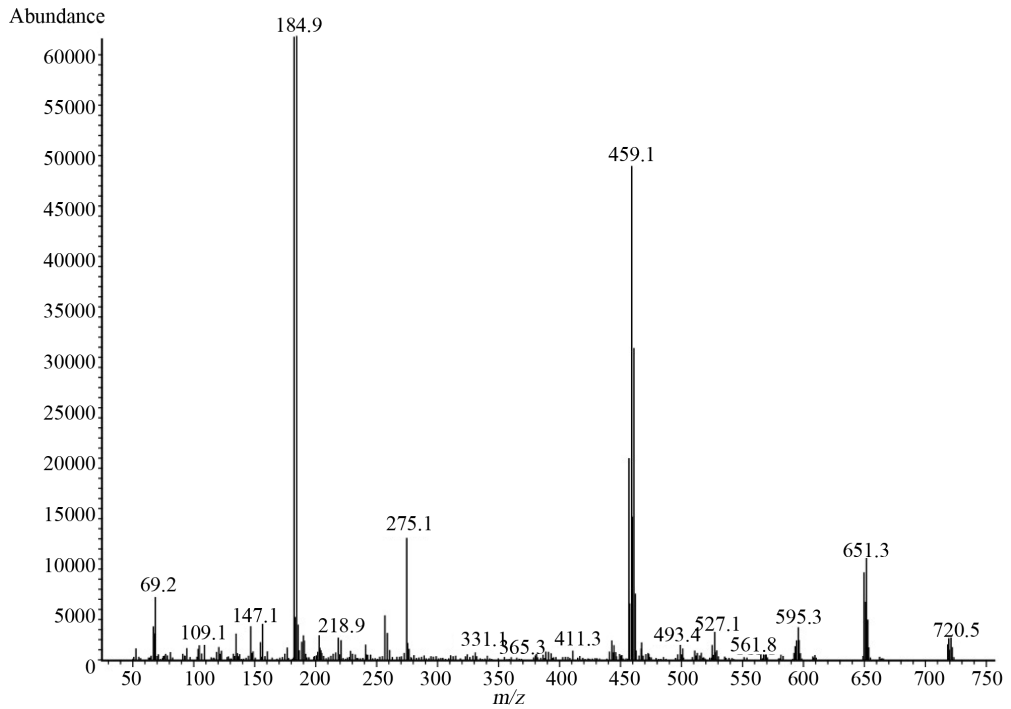

Figure 5. Mass spectrum of peak A, the minor isomer of the p-bromobenzoate ester of hyperforin.

enol tautomerism, characterized by transfer of a hydrogen atom within the same molecule. The keto and enol forms exist as tautomers of each other. This isomerism qualifies as tautomerism by virtue of the interconversion of the two forms involving the movement of a proton and the shifting of bonding electrons. Rapid tautomeric equilibrium between a keto form (a ketone or an aldehyde) and an enol (an alcohol) (see Figure 8), which contains a pair of doubly bonded carbon atoms adjacent to a hydroxyl $(-\mathrm{OH})$ group, is highly thermodynamically driven (see Figure 9) and specific $\mathrm{pH}$ can favor one of the tautomeric forms. During the application of a molecule of hyperforin at room temperature and in the presence of derivatizing agents, the conditions are favorable for the derivative (1) in Figure 3 as a major product. However, a minor derivative A was also present in a TIC chromatogram (Figure 4) and a mass spectrum (Figure 5). Use 


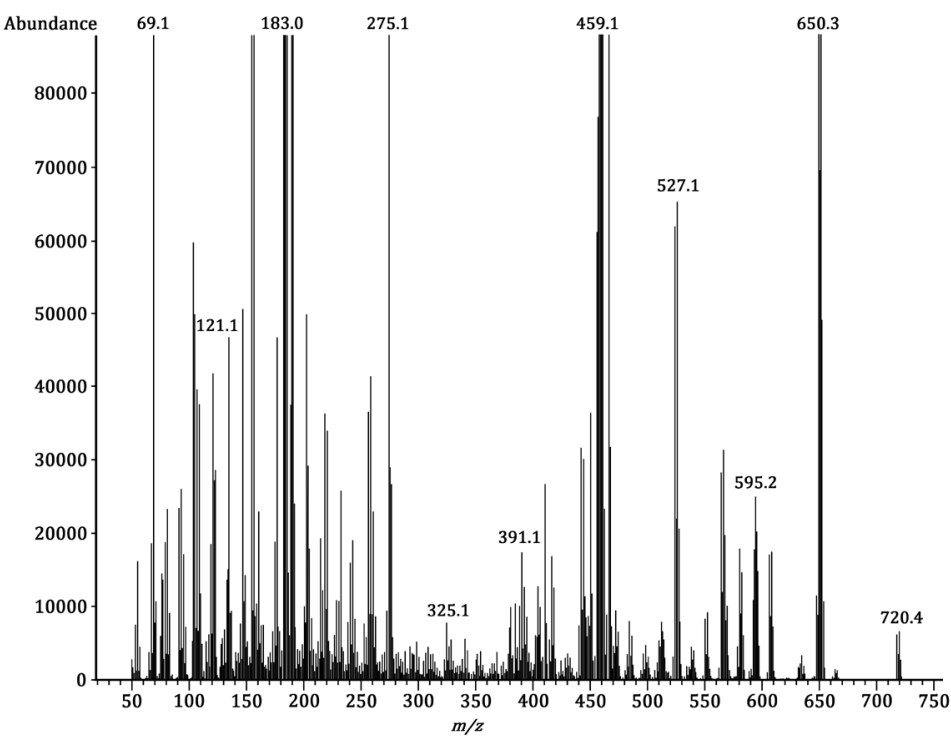

Figure 6. Mass spectrum of peak B, the major isomer of the p-bromobenzoate ester of hyperforin.

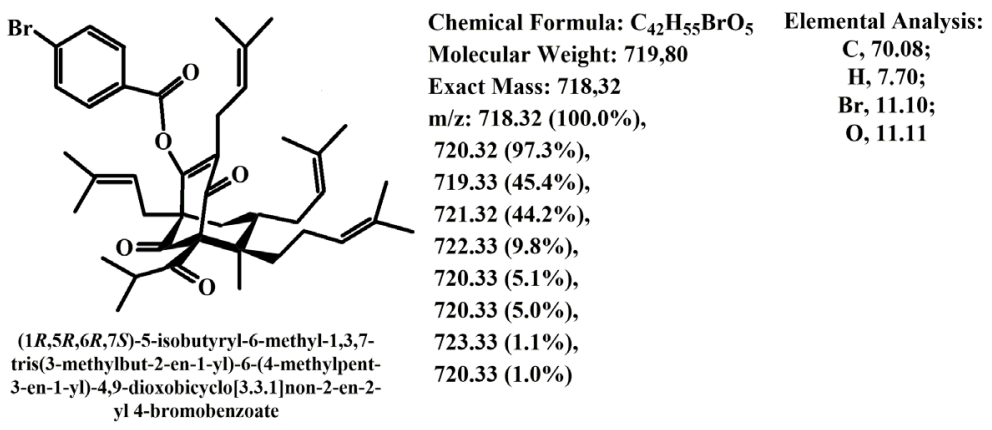

Figure 7. p-Bromobenzoate ester of hyperforin [16] together with percentage composition of elements in crystals analyzed by oxidative analysis, and Molecular weight calculated (in Dalton) and mass $\mathrm{m} / \mathrm{z}$ of $\mathrm{M}+$.<smiles>[R4]C([R])=C([R3])O</smiles>

Figure 8. Tautomeric equilibrium.<smiles>O=C1CCC(=O)c2ccccc21</smiles>

2,3-dihydronaphthalene-1,4-dione

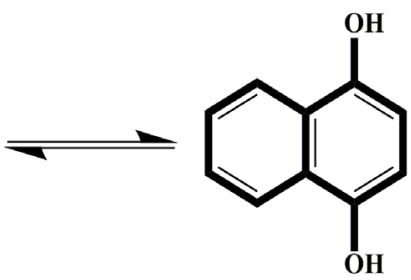

naphthalene-1,4-diol

Figure 9. A specific $\mathrm{pH}$ can favor one of the tautomeric forms. 
of a different $\mathrm{pH}$ from that used in derivatization for the described $p$-bromobenzoate ester of hyperforin major isomer B could lead to the minor isomer A. The production of derivative A could be explained, as shown in Figure 10 and Figure 11. Figure 11 shows the production of the $p$-bromobenzoate ester of hyperforin as the minor derivative A.

The separation of these two stereomers, A and B, was possible with an achiral column because they are diastereomers and differ in terms of their relative structures. Diastereomers are substances that differ in terms of their physicochemical parameters; they have different melting and boiling points. The prevalence of the A or B isomer in natural hyperforin, and in the stomach, blood, lymph, and body treasures, can strongly depend on the $\mathrm{pH}$ and cations in electrolytes. Because isomer A of hyperforin is different from isomer B of hyperforin, I propose it be referred to as perforatrin.

\subsection{Stereochemistry of Hyperforin Proposed by Brondz}

$\mathrm{X}$-ray crystallographic analysis is generally accepted as proof of the stereochemistry of previously unknown molecules. However, in order to finalize any discussions, it is important to obtain independent evidence and decisive proof. The

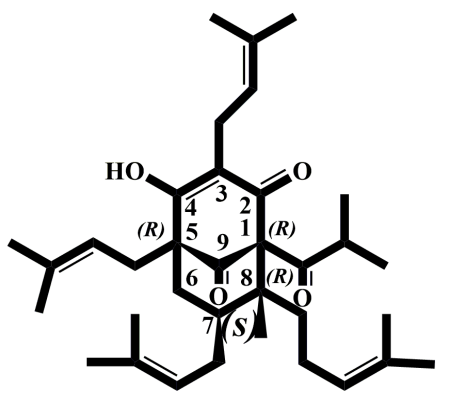

$(1 R, 5 R, 7 S, 8 R)-4$-hydroxy-1-isobutyryl-8methyl-3,5,7-tris(3-methylbut-2-en-1-yl)8-(4-methylpent-3-en-1yl)bicyclo[3.3.1]non-3-ene-2,9-dione

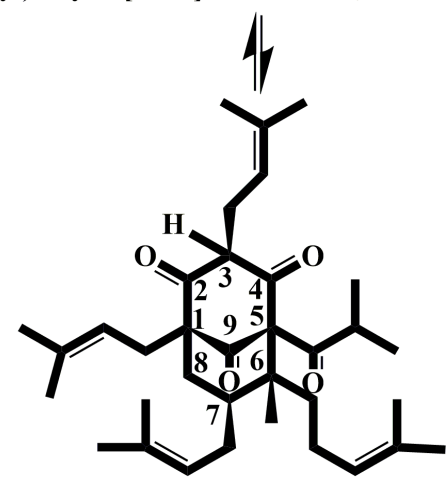

$(1 R, 3 R, 5 R, 6 R, 7 S)-5$-isobutyryl-6-methyl1,3,7-tris(3-methylbut-2-en-1-yl)-6(4-methylpent-3-en-1yl)bicyclo[3.3.1]nonane-2,4,9-trione

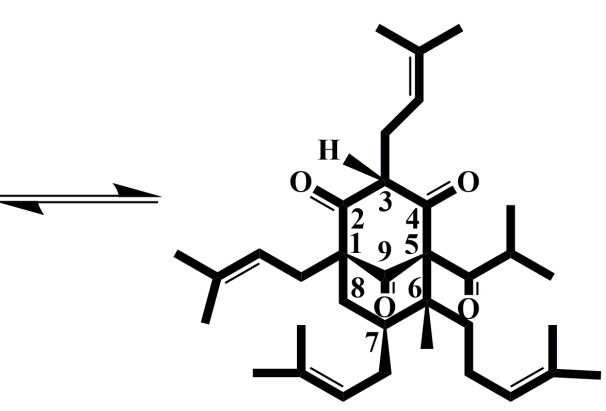

$(1 R, 3 S, 5 R, 6 R, 7 S)$-5-isobutyryl-6-methyl1,3,7-tris(3-methylbut-2-en-1-yl)-6-(4methylpent-3-en-1-

yl)bicyclo[3.3.1] nonane-2,4,9-trione

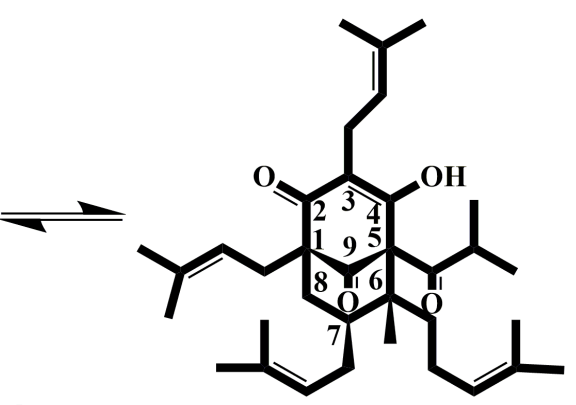

$(1 R, 5 S, 6 R, 7 S)$-4-hydroxy-5-isobutyryl-6methyl-1,3,7-tris(3-methylbut-2-en-1-yl)-6(4-methylpent-3-en-1-yl)bicyclo[3.3.1]nonane2,9-dione

Figure 10. All molecules shown could exist in the mixture together with underivatized major isomer hyperforin. 


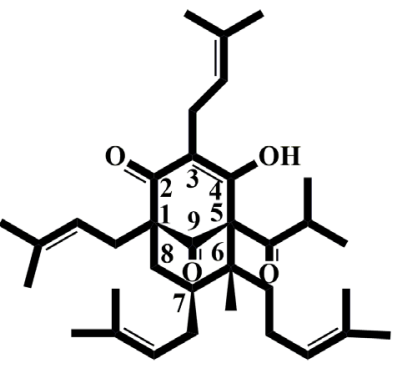

$(1 R, 5 S, 6 R, 7 S)$-4-hydroxy-5-isobutyryl-6methyl-1,3,7-tris(3-methylbut-2-en-1-yl)-6(4-methylpent-3-en-1-yl)bicyclo[3.3.1]nonane2,9-dione

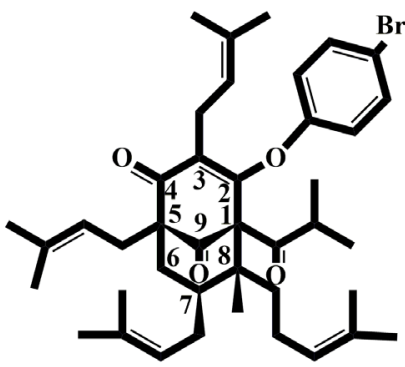

$(1 S, 5 R, 7 S, 8 R)$-1-isobutyryl-83,5,7-tris(3-methylbut-2-en-1yl)-8-(4-methylpent-3-en-1-yl)-4,9dioxobicyclo[3.3.1]non-2-en-2yl 4

bromobenzoate

Figure 11. Production of $p$-bromobenzoate ester of hyperforin from minor derivative A.

total synthesis or in case of plant metabolite the structure elucidated from biosynthesis of the molecule in question offers such proof.

In 2013, Shair et al. reported on the results of the enantioselective synthesis of hyperforin in J. Am. Chem. Soc. [20]. The structure is presented there, and reproduced here in Figure 12, with the addition of the authors' numbering of the $\mathrm{C}$ atoms, following IUPAC conventions for the numbering of $\mathrm{C}$ atoms, and their chirality.

In 2010, a paper entitled 'Catalytic Asymmetric Total Synthesis of entHyperforin' by Yohei Shimizu et al. was published [21]. In it, the authors state the following: " ${ }^{1} \mathrm{H},{ }^{13} \mathrm{C} N \mathrm{NR}$, and IR spectroscopic data as well as mass spectrometric data were all identical with the reported values. The optical rotation of synthesized 5 was opposite to that of the natural isomer $\left([a]_{D}^{23}=-36.8(c=0.38\right.$, EtOH); Lit. $+41^{[2] ”}$. Figure 13 shows the structure presented by Shimizu et al. [21] and that of the structure published [16], for comparison. Proving that the $\mathrm{X}$-ray structure of hyperforin in [16] is identical to that of the synthetic structures in [20] and provides the best evidence for the accuracy of the structure given in [16].

In Figure 3, the two-dimensional structure (3) was deduced from structure (2) of hyperforin. Structures presented in Figure 12 [20] as hyperforin and hyperforin Figure 13(1) in [21] have the same IUPAC name and chirality as hyperforin in Figures 3(3) and Figure 13(4) [16]. The structures published in [20] [21] are identical to the structure of substance proposed in [16], and it is proven by two decisive analyses [20] [21]. Publications [20] and [21] support the earlier elucidation of the relative and absolute stereochemistry of hyperforin by $\mathrm{X}$-ray crystallography, as published in [15] and [16].

\subsection{Challenging the Relative and Absolute Stereochemistry of Hyperforin' Published by Bystrov et al.}

The question here concerns the relative and absolute stereochemistry of hyperforin and whether it is in compliance with what has been described earlier, in 1975 and 1976, by Bystrov et al. (see Figure 1). Despite attempts of Bystrov et al. 


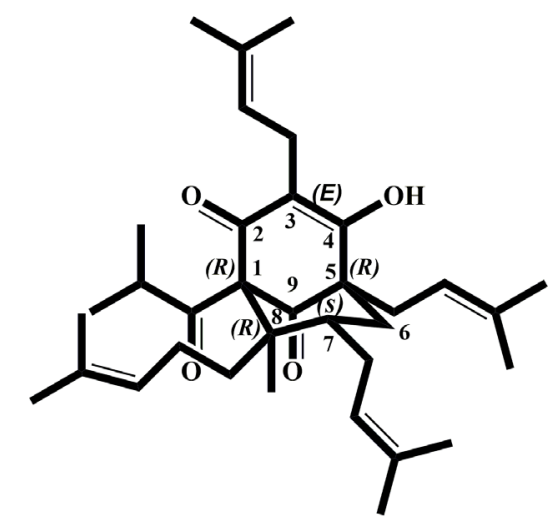

$(1 R, 5 R, 7 S, 8 R)$-4-hydroxy-1-isobutyryl-8-methyl-

3,5,7-tris(3-methylbut-2-en-1-yl)-8-(4-methylpent-

3-en-1-yl)bicyclo|3.3.1|non-3-ene-2,9-dione

Figure 12. Structure of hyperforin presented in [20]. (Name of the substance and numbering of $\mathrm{C}$ atoms following IUPAC convention were added by the author of this paper).
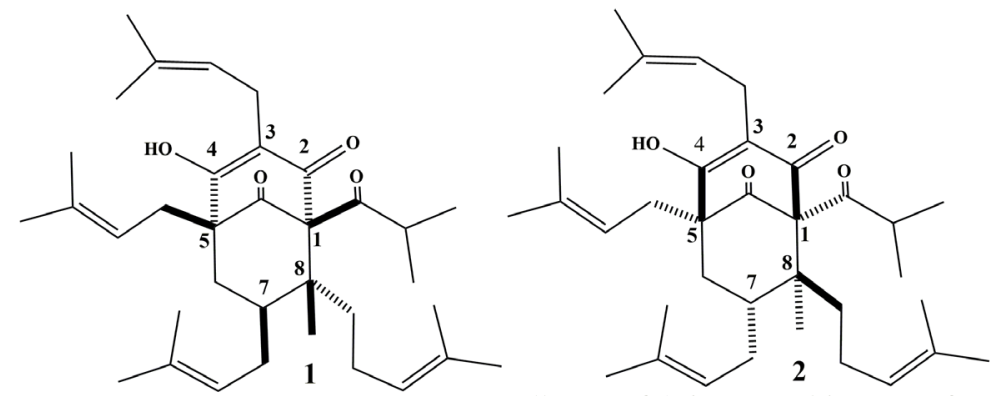

$(1 R, 5 R, 7 S, 8 R)-4$-hydroxy-1-isobutyryl-8 methyl-3,5,7-tris(3-methylbut-2-en-1-yl)-8-
(4-methylpent-3-en-1-yl)bicyclo[3.3.1]

$(1 S, 5 S, 7 R, 8 S)$-4-hydroxy-1-isobutyryl-8methylpent-3-en-1-yl)bicyclo[3.3.1]non-3-ene non-3-ene-2,9-dione

2,9-dione

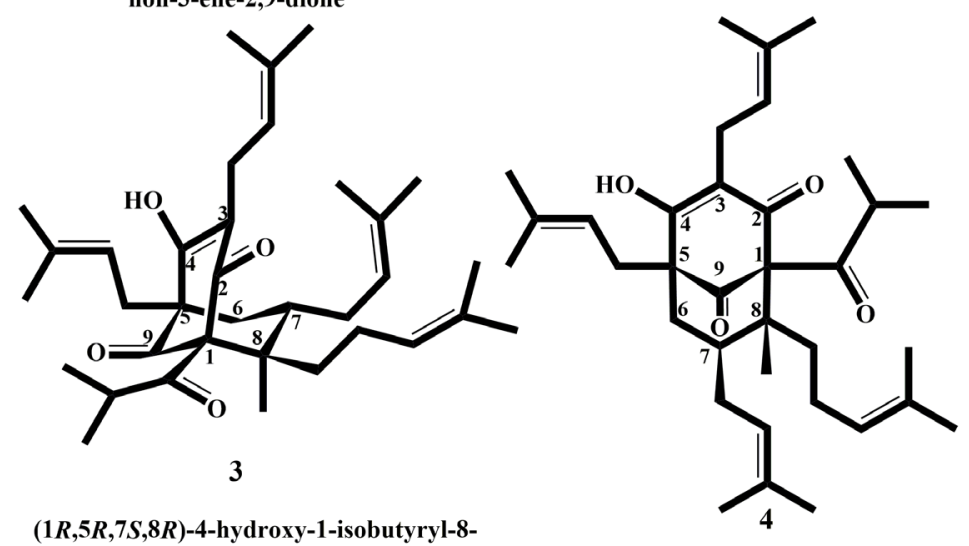

methyl-3,5,7-tris(3-methylbut-2-en-1-yl)-8 (4-methylpent-3-en-1-yl)bicyclo[3.3.1] $\quad$ methyl-3,5,7-tris(3-methylbut-2-en-1-yl)-8 -
(1 $R, 5 R, 7 S, 8 R)-4$-hydroxy-1-isobutyryl-8non-3-ene-2,9-dione (4-methylpent-3-en-1-yl)bicyclo[3.3.1] non-3-ene-2,9-dione

Figure 13. Structures of (1) hyperforin in [21], (2) ent-hyperforin in [21], (3) hyperforin in [16], and (4) hyperforin in [16] in two-dimensional projection.

to present new, however incorrect (because of IUPAC rules), renumbering of $\mathrm{C}$ atoms for the previous structure published in [6] by new numbering publishing in [10] and [11], it is obvious that this is the same structure as presented in 1975 
[6]; the structure is also incorrect in terms of both relative and absolute stereochemistry. Further explanations are given in [22].

\subsection{General Discussion}

It is important to compare the structure of hyperforin published by Bystrov et al. [6], which is identical to the structure given in [11], with the major B [15], [16] (see Figure 14). and minor $\mathrm{A}$ isomers of hyperforin to demonstrate differences (see Figure 15). Here it is obvious that there [6] and [16] are two different molecules, if the numbering of the $\mathrm{C}$ atoms in both molecules follows IUPAC rules. To demonstrate this more clearly, both molecules were divided by arrows on the left $(\mathrm{L})$ and right $(\mathrm{R})$ sides. In molecule (1), the C-6 position is not substituted and is on the left side, while in molecule (2), the C-6 position is substituted and on the right side. In both molecules, the isobutyryl, methyl, and methylpenthyl substituents are from the right side; in molecule (1) the hydroxyl is from the left, but in molecule (2), the hydroxyl is from the right. The keto substituent in molecule (1) is from the right, but in molecule (2), the keto substituent is from the left. Double bonds in the molecules are on opposite sides to each other. From all these described differences, it is clear that we have two different structures, even in terms of relative stereochemistry. This clearly indicates that the structures of Bystrov [6] [11] have nothing in common with the major B isomer of hyperforin [16].

A comparison of the hyperforin' structure of Bystrov with that of the minor A isomer of hyperforin-perforatrin is shown in Figure 15.

Despite many similarities in the positions of substituents in the molecules, they are not identical; they are diastereomers and have different absolute stereochemistry. Incorrect numbering of $C$ atoms is presented in [10] and [11]; it is not in compliance with IUPAC rules. New renumbering of $\mathrm{C}$ atoms [10] [11]

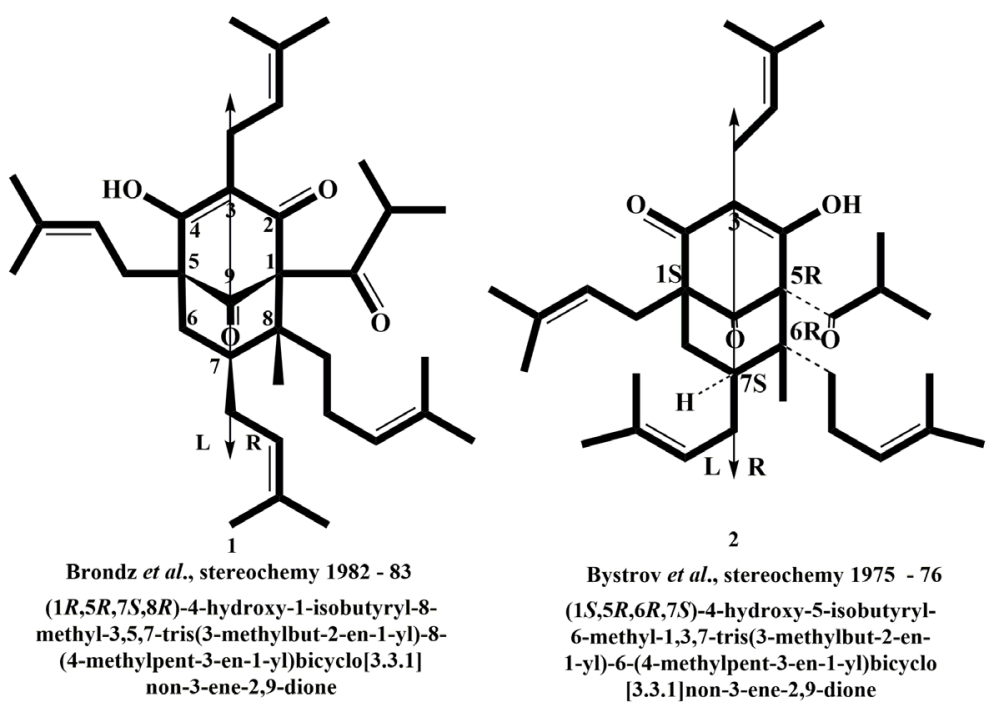

Figure 14. (1) Structure and stereochemistry of hyperforin proposed by Brondz, and (2) structure and stereochemistry of hyperforin proposed by Bystrov et al. 


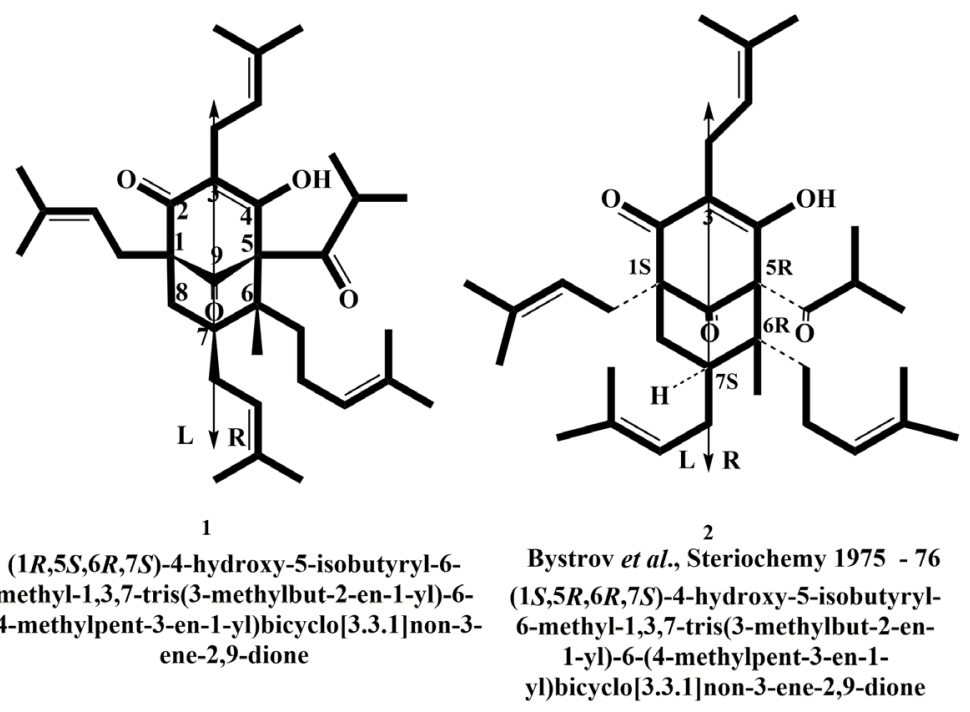

Figure 15. (1) Structure of minor A isomer of hyperforin, which has been named perforatrin, and (2) structure of hyperforin proposed by Bystrov et al.

could not repair the structure presented in 1975 [6] because the major B isomer of hyperforin as it was shown in [15] and [16], and in Figure 14 is different from structure presented in [6] [10] and [11] in relative as well as in absolute stereochemistry, the perforatrin is diasteriomeric to proposed by Bystrov et al., structure of hyperforin in relation to chirality of $\mathrm{C} 1$ and $\mathrm{C} 5$ and stated in [11] $7 R$ and $8 S$ configuration.

In 2004, Zanoli published a review [23] in this publication the structure of hyperforin was presented as figure 1, reproduced in present paper as structure (1) in Figure 16. The structure was not furnished with a description of its stereochemistry. Nonetheless, from the graphical representation and by applying IUPAC rules, it was possible to arrive at the following stereochemical name: $(1 R, 5 R, 7 S, 8 R)$-4-hydroxy-1-isobutyryl-8-methyl-3,5,7-tris(3-methylbut-2-en-1yl)-8-(4-methylpent-3-en-1-yl)bicyclo[3.3.1]non-3-ene-2,9-dione.

In publication [23] was adopted the formula of major B isomer of hyperforin as it presented in Figure 3, and formula of hyperforin Figure 12 as was presented in [20], and formula of hyperforin Figure 13 as was presented in [21]. In all of these publications, the same relative and absolute configuration for the major isomer of hyperforin is $1 R, 5 R, 7 S, 8 R$, which follows from publications [15] and [16]. Figure 16 also shows the structure of hyperforin from the publications of Bystrov et al. Figure 16(2). A more conventional IUPAC interpretation Figure 16(2) is presented as Figure 16(3). Structure (4) in Figure 16 is the result of an attempt to redraw structure Figure 16(3) according to the style used in The Merck Index and in Wikipedia.

The first time that the structure of hyperforin was presented in The Merck Index [24] and later in [25] and in Wikipedia, it was reproduced as structure (5) in Figure 16, it is different in chirality from Figure 16(4).

In Figure 16, (6) presents the transformation of Figure 16(1) by the fashion 


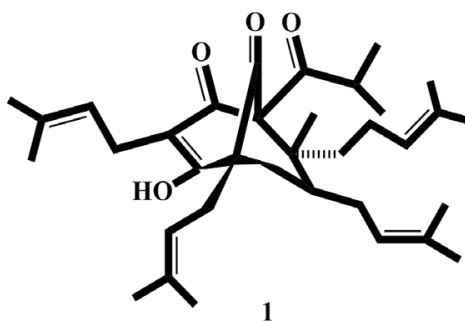

$(1 R, 5 R, 7 S, 8 R)-4$-hydroxy-1-isobutyryl-8methyl-3,5,7-tris(3-methylbut-2-en-1yl)-8-(4-methylpent-3-en-1-yl)bicyclo [3.3.1]non-3-ene-2,9-dione

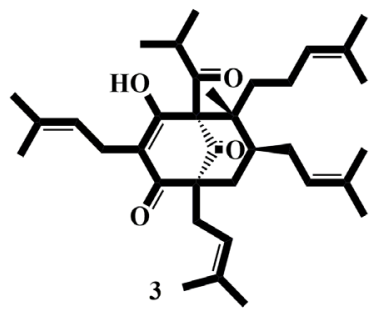

$(1 S, 5 R, 6 R, 7 S)$-4-hydroxy-5-isobutyryl-6methyl-1,3,7-tris(3-methylbut-2-en-1yl)-6-(4-methylpent-3-en-1yl)bicyclo[3.3.1]non-3-ene-2,9-dione

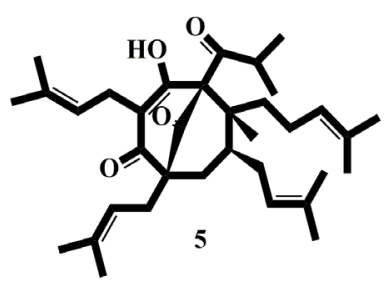

$(1 R, 5 S, 6 R, 7 S)-4$-hydroxy-5-isobutyryl-6methyl-1,3,7-tris(3-methylbut-2-en-1-yl)-6(4-methylpent-3-en-1-yl)bicyclo[3.3.1]non3-ene-2,9-dione

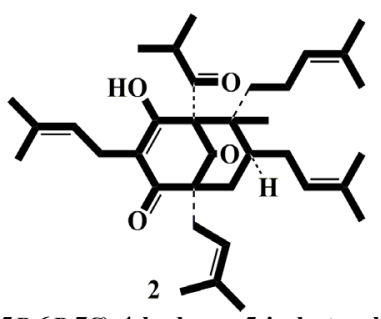

$(1 S, 5 R, 6 R, 7 S)-4$-hydroxy-5-isobutyryl-6methyl-1,3,7-tris(3-methylbut-2-en-1yl)-6-(4-methylpent-3-en-1-yl)bicyclo [3.3.1]non-3-ene-2,9-dione

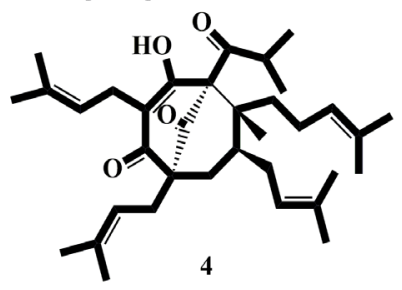

$(1 S, 5 R, 6 R, 7 S)-4-h y d r o x y-5-i s o b u t y r y l-6-$ methyl-1,3,7-tris(3-methylbut-2-en-1-yl)-6(4-methylpent-3-en-1-yl)bicyclo[3.3.1]non3-ene-2,9-dione

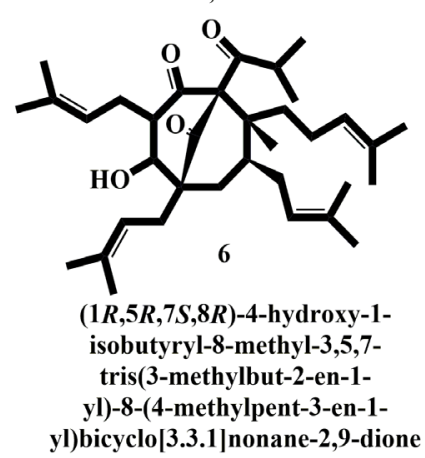

Figure 16. Structures: (1) is the structure of hyperforin as published in a review by Paola Zanoli [23], (2) is the figure taken from the publications of Bystrov et al., (3) is the conventional IUPAC interpretation figure 17, (4) is an attempt to redraw (3) by the fashion used in The Merck Index (2001) [24] [25] and in Wikipedia, (5) is the structure presented in The Merck Index [24] [25] and in Wikipedia, and (6) is the transformation of (1) by the fashion used in The Merck Index (2001) [24] and in Wikipedia.

used in The Merck Index [24] [25] and in Wikipedia, and Figure 16(1) is the stereochemical structure of hyperforin published in [15] [16] [20] [21] and [26]. In 2002, Petra Adam et al. published [26] (see Figure 17) in which the structure of hyperforin was elucidated from biosynthesis of hyperforin in $H$. perforatum "Hyperforin was isolated and analyzed by quantitative NMR spectroscopy" [26]. Graphically presented structure was not furnished with a description of its stereochemistry, however, from the graphical representation and by applying IUPAC rules, it was possible to arrive at the following stereochemical name: $(1 R, 5 R, 7 S, 8 R)$-4-hydroxy-1-isobutyryl-8-methyl-3,5,7-tris(3-methylbut-2-en-1-y 1)-8-(4-methylpent-3-en-1-yl)bicyclo[3.3.1]non-3-ene-2,9-dione. 


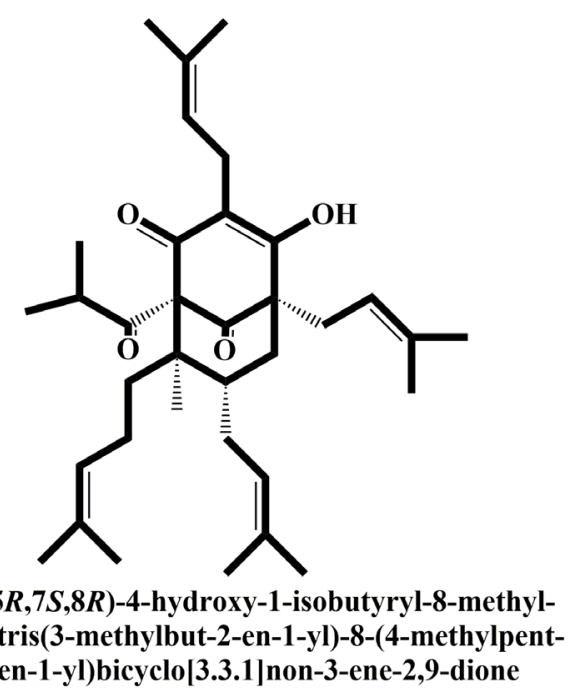

Figure 17. Structure of hyperforin elucidated from biosynthesis of hyperforin in $H$. perforatum [26].

The hyperforin structure which was elucidated from biosynthesis [26] of hyperforin in $H$. perforatum identical to major B isomer and to relative and absolute stereochemistry of hyperforin published in 1982-83 [15] [16].

\section{Conclusions}

Hyperforin has four chiral centers and, theoretically, the existence of 16 different stereoisomers is possible. However, because hyperforin is a secondary metabolite of plant origin and in its biosynthesis the enzymatic reactions take place, the product is highly enantiospecific. For this reason, only one isomer of hyperforin should be expected. However, there are two stable isomers that exist in a dynamic equilibrium because the molecule is a tautomer. Evidence of this was provided by GC-MS with SMB analysis. There are similar cases expected and will be discovered in tautomeric molecules with multiple chiral centers.

It has been proven that the structures of hyperforin as described by Bystrov et al. differ from the major B [16] isomer of hyperforin and from the minor A isomer of hyperforin-perforatrin in terms of both relative and absolute stereochemistry.

The stereochemical structure of hyperforin published in [15] [16] by Brondz et al. is supported by [20] [21] and [26], and it is in compliance with major B isomer of hyperforin presented in this paper. The major pool of hyperforin in plant $H$. perforatum exists as isomer B [26] earlier elucidated by X-ray crystallography in [15] and [16]. Perforatrin minor A isomer was discovered by GC-MS with SMB and was described in this paper.

\section{Acknowledgements}

The author is grateful to Professor Aviv Amirav, School of Chemistry, Tel Aviv University, Tel Aviv, Israel for technical assistance with GC-MS with SMB. 


\section{References}

[1] Gratia, A. (1925) Sur un remarquable example d'antagonisme entre deux souches de colibacille. Compt. Rend. Soc. Biol, 93, 1040-1042. Referred from: Gratia, J.P. (2000) Andre Gratia: A Forerunner in Microbial and Viral Genetics. Genetics, 156, 471-476.

http://www.ncbi.nlm.nih.gov/entrez/query.fcgi?cmd=Retrieve\&db=pubmed\&dopt= Abstrac t\&list_uids=11014798"PMID 11014798

[2] Gratia, J.P. (2000) André Gratia: A Forerunner in Microbial and Viral Genetics. Genetics, 156, 471-476.

http://www.ncbi.nlm.nih.gov/entrez/query.fcgi? cmd=Retrieve\&db=pubmed\&dopt= Abstrac t\&list_uids=11014798"PMID 11014798

[3] Hugh, T.B. (2002) Howard Florey, Alexander Fleming and the Fairy Tale of Penicillin. The Medical Journal of Australia, 177, 52-53.

[4] Maksyutina, N.P. and Koget, T.A. (1971) Polyphenols of the Herb Hypericum perforatum and the Preparation Novoimanin, Chemistry of Natural Compounds, 7, 338-341. https://doi.org/10.1007/BF00569009

[5] Gurevich, A.I., Dobrynin, V.N., Kolosov, M.N., Popravko, S.A., Ryabova, I.D., Chernov, B.K., Derbentseva, N.A., Aizenman, B.E. and Garagulya, A.D. (1971) Hyperforin, an Antibiotic from Hypericum perforatum L. Antibiotiki Kimioterapi, 16, 510-513.

[6] Bystrov, N.S., Chernov, B.K., Dobrynin, V.N. and Kolosov, M.N. (1975) The Structure of Hyperforin. Tetrahedron Letters, 16, 2791-2794.

https://doi.org/10.1016/S0040-4039(00)75241-5

[7] Bystrov, N.S., Dobrynin, V.N., Kolosov, M.N., Popravko, S.A. and Chernov, B.K. (1978) Chemistry of Hyperforin. VI. General Chemical Characterization. Bioorganicheskaya Khimiya, 4, 791-797.

[8] Bystrov, N.S., Dobrynin, V.N., Kolosov, M.N., Popravko, S.A. and Chernov, B.K. (1978) VIII. Differentiation of the Side Chains. Bioorganicheskaya Khimiya, 4, 943-947.

[9] Bystrov, N.S., Dobrynin, V.N., Kolosov, M.N., Popravko, S.A. and Chernov, B.K. (1978) Chemistry of Hyperforin. IX. The Structure of Hyperforin. Bioorganicheskaya Khimiya, 4, 948-955.

[10] Bystrov, N.S., Gupta, S.R., Dobrynin, V.N., Kolosov, M.N., Chernov, B.K., Chervin, I.I., Yakovlev, G.I., Aizenman, B.E. and Derbentseva, N.A. (1976) Structure of the antibiotic Hyperforin. Doklady Akademii Nauk SSSR, 226, 88-90.

[11] Bystrov, N.S., Dobrynin, V.N., Kolosov, M.N., Chernov, B.K., Chervin, I.I. and Yakovlev, G.I. (1976) Stereokhimiya Antibiotika Hyperforina. Doklady Akademii Nauk SSSR, 226, 338-341.

[12] Brondz, I. (1979) Antibiotikumet "Hyperforin" og andre innholdsstoffer i drogen Hypricum perforatum $\mathrm{L}$. Thesis, University of Oslo, Oslo. (In Norwegian)

[13] Brondz, I., Greibrokk, T. and Aasen, A.J. (1983) n-Alkanes of Hypericum perforatum: A Revision. Phytochemistry, 22, 295-296. https://doi.org/10.1016/S0031-9422(00)80110-7

[14] Brondz, I., Greibrokk, T. and Aasen, A.J. (1983) n-1-Alkohols of Hypericum perforatum. Journal of Natural Products, 46, 940-941. https://doi.org/10.1021/np50030a025

[15] Brondz, I., Greibrokk, T., Groth, P.A. and Aasen, A.J. (1982) The Relative Stereochemistry of Hyperforin-An Antibiotic from Hypericum perforatum L. Tetrahe- 
dron Letters, 23, 1299-1300. https://doi.org/10.1016/S0040-4039(00)87088-4

[16] Brondz, I., Greibrokk, T., Groth, P. and Aasen, A.J. (1983) The Absolute Configuration of Hyperforin, an Antibiotic from Hypericum perforatum L., Based on the Crystal Structure Determination of its p-Bromobenzoate Ester. Acta Chemica Scandinavica, A37, 263-265. https://doi.org/10.3891/acta.chem.scand.37a-0263

[17] Brondz, I., Fialkov, A.B. and Amirav, A. (2009) Analysis of Quinocide in Unprocessed Primaquine Diphosphate and Primaquine Diphosphate Tablets Using Gas Chromatography-Mass Spectrometry with Supersonic Molecular Beams. Journal of Chromatography A, 1216, 824-829. https://doi.org/10.1016/j.chroma.2008.11.043

[18] Amirav, A. (2013) What Can Be Improved in GC-MS-When Multi Benefits Are Transformed into a GC-MS Revolution. International Journal of Analytical Mass Spectrometry and Chromatography (IJAMSC), 1, 31-47. https://doi.org/10.4236/ijamsc.2013.11005

[19] Brondz, I. (2013) Structure Elucidation of a New Toxin from the Mushroom Cortinarius rubellus by Using Gas Chromatography-Mass Spectrometry (GC-MS). International Journal of Analytical Mass Spectrometry and Chromatography, 1, 109-118. http://dx.doi.org/10.4236/ijamsc.2013.12014

[20] Sparling, B.A., Moebius, D.C., Matthew, D. and Shair, M.D. (2013) Enantioselective Total Synthesis of Hyperforin. Journal of the American Chemical Society, 135, 644-647. https://doi.org/10.1021/ja312150d

[21] Shimizu, Y., Shi, S.-L., Usuda, H., Kanai, M. and Shibasaki, M. (2010) Catalytic Asymmetric Total Synthesis of ent-Hyperforin. Angewandte Chemie International Edition, 49, 1103-1106. https://doi.org/10.1002/anie.200906678

[22] Brondz, I. (2017) Super Antibiotics, Part III. Hyperforin, Revision of Relative and Absolute Stereochemistry Proposed by Bystrov et al. Voice of the Publisher, 3, 1-10. https://doi.org/10.4236/vp.2017.32002

[23] Zanoli, P. (2004) Role of Hyperforin in the Pharmacological Activities of St. John's Wort. CNS Drug Reviews, 10, 203-218. https://doi.org/10.1111/j.1527-3458.2004.tb00022.x

[24] (Eds.: O’Neil, M.J., Smith, A., Heckelman, P.E., Obenchain, J.R., Gallipeau, J.A.R. and D'Arecca, M.A., Eds. (2001) The Merck Index, an Encyclopedia of Chemicals, Drugs, and Biologicals. 13th Edition, Merck Research Laboratories Division of Merck \& Co., Inc., Whitehouse Station, NJ, 871.

[25] The Merck Index Online. https://www.rsc.org/Merck-Index/searchresults?searchterm=Hyperforin

[26] Adam, P., Duilio Arigoni, D., Bacher, A. and Eisenreich, W. (2002) Biosynthesis of Hyperforin in Hypericum perforatum. Journal of Medicinal Chemistry, 45, 4786-4793. https://doi.org/10.1021/jm0209782 
Submit or recommend next manuscript to SCIRP and we will provide best service for you:

Accepting pre-submission inquiries through Email, Facebook, LinkedIn, Twitter, etc. A wide selection of journals (inclusive of 9 subjects, more than 200 journals)

Providing 24-hour high-quality service

User-friendly online submission system

Fair and swift peer-review system

Efficient typesetting and proofreading procedure

Display of the result of downloads and visits, as well as the number of cited articles Maximum dissemination of your research work

Submit your manuscript at: http://papersubmission.scirp.org/

Or contactijamsc@scirp.org 